\title{
A SEMANTICALLY ENRICHED AND WEB-BASED 3D ENERGY MODEL VISUALIZATION AND RETRIEVAL FOR SMART BUILDING IMPLEMENTATION USING CITYGML AND DYNAMIZER ADE
}

\author{
E. Chatzinikolaou ${ }^{1, *}$, I. Pispidikis $^{1}$ and E. Dimopoulou ${ }^{1}$ \\ ${ }^{1}$ School of Rural and Surveying Engineering, National Technical University of Athens, 9, Iroon Polytechneiou str, \\ Zografou 15780 - e.chatz175@gmail.com, pispidikisj@yahoo.gr, efi@survey.ntua.gr
}

\section{Commission VI, WG VI/4}

\begin{abstract}
KEY WORDS: Dynamizer ADE, CityGML, BIM, BEM, 3DCityDB, Energy Time-series, Smart Building, CityGML
\end{abstract} RESTful Web service, SWE

\begin{abstract}
:
Smart Cities are complex distributed systems which may involve services, applications, sensors and IoT devices. In order to be able to link and use such heterogeneous data, spatial data infrastructures for Smart Cities can play an important role in establishing interoperability between systems and platforms. Semantic 3D city models describe spatial, graphical and thematic aspects of the city objects according to the CityGML international standard, issued by the Open Geospatial Consortium (OGC). The requirement to support energy time-dynamic properties within CityGML objects arises from the fact that cities yield great potential in terms of energy consumption reduction and efficiency increase. In order to support such time-varying energy properties concerning city objects, recent extensions of the CityGML in the form of Application Domain Extensions (ADEs) are researched and developed, such as the Energy ADE and the Dynamizer ADE. Starting from a Building Information Model (BIM) and evaluating energy use of the building through the created Building Energy Model (BEM), the aim of this study is to integrate and visualize the time-based energy simulation results with the 3D building model within a 3D semantic city model. Using the latter ADE, the highly detailed static 3D Building (LOD 4) is extended to support those energy variations of individual feature properties and associations over time. Moreover, the web-based visualization approaches and data retrieval were further researched, and an interoperable web-based application was developed, in order to accomplish an integrated knowledge on how time-series data can be distributed in a virtual 3D environment.
\end{abstract}

\section{INTRODUCTION}

\subsection{Introduction - Research Objectives}

Cities include plenty of application domains, where time plays an important role. Most of these city applications involve scenarios, where city object properties are not static and change over time. Changes in cities can also be categorized based on their frequencies; either could be slower in nature or present high frequent or dynamic variation (Chaturvedi et al., 2017). Temporal variations of a building can be determined for specific points of time and onto specific attributes. For example, varying energy consumption values of a building can refer to (i) the past by querying a database for historic data, (ii) the present by querying a real-time sensor, and to (iii) the future, by a simulation software (Chaturvedi and Kolbe 2019).

Chaturvedi and Kolbe (2019) also enlist different application domains, where Semantic 3D City Models need to be extended in order to support time-dependent properties. Those applications are categorized based on geometry and thematic information, topology and appearance, in the concept of how time affects every category.

This paper highlights the need for that temporal extension of Semantic 3D City Models in order to create a geospatiallyenabled smart web-application, supporting the time-dependent dynamic energy properties of building objects, by using both real/ measured and simulated time-series data. Further on, the examined case study evaluates the degree of interoperability of the three most popular semantically enriched standards, OGC CityGML (version 2.0), buildingSMART IFC (version 4) and
gbXML (Version 6.01) to be used in smart cities applications. Moreover, it underlines the possibilities provided by CityGML extensions, Energy ADE (Aguriano et al., 2018) and Dynamizer ADE (Chaturvedi and Kolbe, 2016), focusing on the latter, in order to manipulate dynamic variations in the form of timeseries associating with energy parameters. Finally, the webbased visualization approaches and data retrieval are further researched and presented. As a result, an interoperable webbased application was developed in order to accomplish an integrated knowledge, on how time-series data can be distributed in a virtual 3D environment.

\subsection{Semantic 3D City Models for Building Energy Efficiency in Smart Cities}

The concept of Smart Cities allows for the effective integration of human, physical and digital systems operating in the built environment, thus, improving the support of citizens and city governance in the field of a rapidly increasing urban environment. This concept encompasses the management of city resources, such as energy and water, with the help of advanced information and communication technologies (ICT), such as sensors and the Internet of Things (IoT), Big Data, Cloud Computing, and geospatial technologies. Sensors and IoT devices may be air quality sensors, weather stations (e.g. monitoring temperature, humidity etc.) or even smart meters (measuring real-time electricity consumption). The rapid evolution of those technological sectors in the concept of Smart Cities also requires increasingly detailed Semantic 3D City Models, to maximize their effectiveness, as the data streams from these sources cannot be integrated and analyzed without 
modelling their location in 3D space (Batty et al., 2012). Semantic 3D City Models describe not only spatial and graphical aspects of the city objects, but also provide ontological structure, including thematic classes, attributes, and their interrelationships. CityGML, issued by the Open Geospatial Consortium (OGC) and Industry Foundation Classes, developed by buildingSMART (IFC, 2016), are very popular international standards for modelling and exchanging Semantic 3D City and Building Information Models (BIM) accordingly.

The growing population of the cities and their concern for the increasing greenhouse gas emission, challenge for effective strategies on how to guarantee and manage basic services (e.g. energy, water), resulting in the reduction in the relevant environmental impact. Appliances like smart meters, better performing materials and digital tools, contribute to energy efficiency and can help consumers to control their energy consumption. Adapting the requirements of the associated Energy Efficiency Directives for Buildings (2010/31/EU, $2012 / 27 / \mathrm{EU}$ ) in the cities, a comprehensive knowledge of the recorded demand and supply of energy resources of the smart meters, including their spatial distribution within urban areas is of utmost importance (Agugiaro et al., 2018).

As regards the Urban Energy Modelling sector, the semantically enriched Green Building XML schema (gbXML) using a Building Energy Model (BEM) is used for sharing building information between disparate building design and Building Energy Simulation software (BES). gbXML file includes all of the information about the building (elements and attributes) that needs to perform an HVAC load calculation or building energy analysis.

Semantic 3D CityGML models are gaining ground with their increasing application in more cities (e.g. Berlin, Singapore, Paris, Zurich), but due to their static nature they are missing time- dependent variations. However, Semantic 3D City Models can provide a means for interactive and spatio-semantic queries and aggregations for numerous application domains (Chaturvedi and Kolbe, 2019). In the framework of smart cities applications, the concept of Smart District Data Infrastructure (SDDI) integrates dynamic data (such as real-time sensor observations) with city objects and focuses on providing interoperability of sensors using

OGC Sensor Web Enablement (SWE) and web-based access to the 3D city objects using OGC Web Feature Service (WFS) (Moshrefzadeh et al., 2017). Similarly, the Future City Pilot Phase 1 (FCP1), an initiative from OGC (OGC FCP1, 2016) focuses on the interoperability between the two international standards, IFC and CityGML, supporting real-time sensor readings and other time-dependent properties within semantic $3 \mathrm{D}$ city models. The latter defines the new concept 'Dynamizer', which provides both an explicit way to model dynamic variations in the form of time-series and a method for injecting dynamic values of city object properties into the static representations, overriding the static value of the referenced object attribute. It also establishes explicit links between sensor/observation data and the respective properties of city model objects that are measured by them.

\section{INTEROPERABILITY OF MODELS}

The following section presents different data exchange formats (IFC - gbXML - CityGML) among various application domains and an overview of their degree of interoperability at different levels of detail. Moreover, it highlights the possibilities of
CityGML Extensions (Dynamizer ADE and Energy ADE) to support dynamic variations of measured or energy simulated properties, leading to geospatially-enabled smart applications.

\subsection{Interoperability of IFC and gbXML}

Many studies focus on the effort to achieve interoperability between BIM and BEM, saving time to the energy simulation process. The data formats that commonly facilitate BIM to BEM interoperability are gbXML and IFC, both data formats capable of extracting and transferring geometrical information from BIM models (Ivanova et al., 2015).

Fernald et al. (2018), highlight key issues that were foreseen to affect the translation process. The quality of the architectural BIM, level of geometrical inconsistencies, or completeness of space enclosures, the user's level of expertise would have an impact on the degree of success of the translation. A successful translation is suggested to carry information related to the following domains: 1) building geometry, construction and material definitions, 2) HVAC systems, controls, and supporting systems and 3) internal loads, building use, and operations (Bazjanac, 2009). In the BIM to BEM integration process, Revit is the appropriate software that creates on the same time semantical rich models. This software can export the IFC Model directly to gbXML, using either energy settings or analytical spaces and rooms. The former approach concludes with a semantically enriched energy model but with geometrical inconsistencies on the contrary to the latter approach that gives a geometrical coherent model but semantically incomplete for an energy simulation. The more sophisticated the model is, the less interoperability results.

Studies regarding the geometrical extraction from native BIM formats into energy modelling tools such as OpenStudio, Virtual Environment, and Insight360 conclude that the BIM to BEM integration efforts lead to geometrical inconsistencies, or completeness of space enclosures and need manual model simplification and correction effort (Fernald et al., 2018). To overcome those difficulties and to minimize errors and inconsistencies, the BEM modelling guidelines should be considered when a BIM is constructed.

\subsection{Interoperability of IFC and CityGML}

BIM and GIS originate from different domains and have different purposes on different scales. IFC, the exchanging standard of BIM, is for detailed 3D building model creation and sharing, while CityGML, referred to as 3D GIS, is for geospatial and non- geospatial semantic data management and analysis. The benefits from their integration are emphasized in the intensive research in this field, as IFC focuses on the building modelling aspect, while CityGML focuses on the city modelling part. The core differences between these data models relate to the main obstacles for the transformation procedure. IFC and CityGML differ widely in terms of geometrical and semantic models of information, as well as in the concept of LoD. Transforming semantic information from IFC to CityGML needs to tackle problems due to semantic mismatches between the classes in the two models, like the entity of the IFC model (eg. IfcWall) that can correspond to different classes of CityGML (e.g. Bldg:WallSurface and Bldg:InteriorWallSurface). Similarly, transforming geometries from IFC to CityGML needs to apply rules to eliminate geometrical ambiguities of the translation, like incoherence between the solid IfcWall geometry and the boundary representation (b-rep) of the Wall in CityGML. 
Mignard and Nicolle (2014) discussed that nearly all the proposals for integrating IFC and CityGML at data level led to similar problems, which include little/partial semantic information about the building, data loss (semantics and/or geometry) in the transformation process, and lack of management of building and geographical elements in a single model. The spatial Extract Transform Load (ETL) process is used by FME as a conversion tool, supporting a bidirectional reading and writing between IFC and CityGML (Donkers, 2013). Rafiee et al. (2014) suggest a step-by-step description on how to integrate BIM data into a spatial information model by ETL Furthermore, Boyes et al. (2017) examine the conversion of IFC geometries to 3D GIS via FME, summarizing the challenges that occur due to limited support for Constructive Solid Geometry (CSG) by FME Workbench, while the generated geometries from Trimble SketchUp are a workable alternative solution. On the contrary with the lower levels of detail focussed on building structure, a manual intervention is required for a higher level of detail (LoD4) using FME. Floros et al. (2018) also highlight that the separation and manipulation of the entities in order to generate a LoD 4 model is more challenging compared to a LoD 3 model, since the interior of a building encloses more geometric and semantic information than its exterior. Additionally, Athanasiou et al. (2019) examined the translation of the SketchUp model to CityGML format using the CityEditor tool and they concluded that the rule-based classification engine seems to automate the process on the translation to the exterior building shell, room shells and the exterior shell of each building storey but not for the rest of the components. An alternative approach for converting IFC to CityGML was presented by Lim et al. (2019). More specifically, they presented various ways on how attribute values can be stored in IFC and CityGML respectively and identify patterns that bridge these endpoints in the conversion process.

\subsection{Interoperability of gbXML and CityGML}

CityGML and gbXML, are both based on XML. CityGML already offers different levels of detail (LoD) and provides an approximate representation of the overall building volume. Relevant characteristics of CityGML 2.0 models are the building's year of construction, different functional classifications of the building, the building height and/or number of storeys and geographic coordinates. Building orientation effects or the influence of neighbouring structures can be taken into account in energy analysis. However, CityGML lacks relevant features for material properties, and the building structure does not directly match the space-oriented structure (thermal zones) of gbXML. Despite lacking precise information about glazed surfaces, LoD1 and LoD2 models of CityGML proved to be geometrically more relevant to gbXML structure (Agugiano et al., 2018; Geiger et al., 2018). On the other hand, LoD3 geometrical representation is generally not directly suitable for the most energy simulation tools as BES works by simplifying assumptions about the thermal energy exchange between the building's thermal boundaries and LoD3 models take into account architectural details.

Models at LoD4 have the highest information content and could, potentially - after adequate geometric processing represent different thermal zones within a building. Lilis et al. (2016), suggest a district space boundary topology generation algorithm for LoD2-4, since CityGML is not directly usable for energy simulation purposes.

\subsection{Supporting energy dynamic properties with CityGML}

According to the general Application Domain Extension (ADE) mechanism, the Energy ADE defines a number of new feature classes and extends the existing classes Building and BuildingPart with additional, energy relevant properties. Version 1.0 of the new data model is comprehensively introduced in (Agugiaro et al., 2018). The extension of CityGML, Energy ADE, provides a model to overcome data interoperability issues for energy-related applications. However, data interoperability among Energy ADE and the heterogeneous software tools of urban energy simulation is out of the scope of this paper. Chatuverdi and Kolbe (2019) are also suggesting that the time-series concept from Dynamizer ADE is going to be applied to Energy ADE.

Dynamizer (Chaturvedi and Kolbe, 2016) is a new concept, which extends static 3D city models by supporting variations of individual feature properties over time. Dynamizers also provide a way to model such dynamic variations with explicit time-series representations. Dynamizers utilize standardized encodings, such as the OGC TimeseriesML standard. Utilizing TimeseriesML, the time-series can be represented as interleaved time/value pairs or by a domain range encoding with the metadata of time-series and timepoints. The time-series values may either be stored directly in-line within the CityGML document or separately in individual tables. Dynamizers have already been implemented as an ADE for CityGML 2.0 and are planned to become part of the next version of CityGML (version 3.0). The new Dynamizer module (CityGML v3) has been developed to improve the usability of CityGML for different kinds of simulations as well as to facilitate the integration of sensors with 3D city models. The integration of sensors with 3D city models is important e.g. in the context of smart cities and digital twins. Both, simulations and sensors, provide dynamic variations of some measured or simulated properties like, for example, the electricity consumption of a building. The variations of the value are typically represented using time series data. The data source of the time series data is either sensor observations (e.g. from a smart meter), prerecorded load profiles (e.g. from an energy company), or the results of some simulation run. A new feature type Dynamizer will represent special objects linking the time series data to a specific attribute (e.g. geometry, thematic data, or appearance) of a specific object within the 3D city model. In this way, dynamic variations of city object properties can be injected into an otherwise static representation (Chaturvedi and Kolbe, 2019).

\section{WEB-BASED VISUALIZATION AND DATA RETRIEVAL APPROACHES OF CITYGML MODEL}

CityGML presents an efficient solution for the representation and exchange of 3D city models. However, the visualization of CityGML models on the web is still a challenging area, since CityGML is designed for the representation of 3D city models and not for presenting or visualizing 3D city models directly on the web (Ohori et al., 2018). Hence, several research works have focussed on the aforementioned challenge for retrieving and visualizing CityGML data, implementing various approaches such as (i) 3D graphics and data exchange formats (ii) tiled and hierarchical-based formats and (iii) $3 \mathrm{D} \mathrm{Web}$ services. 


\subsection{D graphics and data exchange formats}

The increased focus on HTML5 and WebGL solutions leads to the development of various platforms for 3D geospatial data visualizations, such as Cesium, iTown and Javascript API for ArcGIS. The keyhole Markup Language (KML) and the GL Transmission Format (glTF) are natively supported by these frameworks. Specifically, the KML supports the tiled-based retrieval of the data, implementing the NetworkLink element and thus, the progressive web visualization of the huge CityGML model is achieved (Chaturvedi, 2015; Prandi et al., 2015; Yao et al., 2018). The gITF is an API-neutral runtime asset delivery format that provides an efficient, extensible, interoperable format for the transmission and loading of 3D content (Khronos Group, 2019). The implementation of glTF format for streaming CityGML 3D City Models was described by Schilling et al. (2016). They concluded that using formats such as X3D, KML/COLLADA or gITF, makes the rendering process using existing visualization frameworks particularly simple. However, these pure graphics formats cannot directly store CityGML's semantic information. Similarly, Ohori et al. (2018) noted that the visualization of CityGML over the web using commonly 3D graphics requires the separation of geometric information from semantic information. Consequently, the rich semantics of CityGML are often lost.

\subsection{OGC 3D Tiles and OGC I3S}

The format that merges gITF assets and attributes was developed and shared under the umbrella of the OGC 3D tiles (Cozzi, 2019) and called Batched 3D Model (B3DM). This format introduces the concept of batches for identifying objects and assigning properties such as unique ID, feature type and custom attributes. An alternative OGC format for packaging and streaming large, heterogeneously distributed 3D data is the I3S (Indexed 3D Scene Layer), which was released to the community by ESRI and was adopted in 2017 as an OGC standard (Reed \& Belayneh, 2017). A single I3S data set, referred to as a Scene Layer, is designed to provide clients access to data. This data refers to vertex geometry, texture as well as any associated attributes. Currently, the scene layers can be consumed from any ArcGIS applications such as ArcGIS Pro, ArcGIS Earth, ArcGIS online, CityEngine, either as service or local scene layer package files (SLPK).

\subsection{D Web Services}

The demand for serving large scale 3D City Models and spatial data, reflects the need of hierarchical data structures for $3 \mathrm{D}$ data, such as OGC I3S and OGC 3D Tiles. Although these formats can transmit arbitrary sized geospatial data, they are not interoperable with consuming and visualization on the client (Koukofikis et al., 2018).

3.3.1. OGC 3D Portrayal Service (3DPS): The OGC 3DPS standard (Hagedorn et al., 2017) has been designed to enable the interoperable visualizations between various data providers and different browsers based on 3D globes and other viewer implementations (Gutbell et al., 2016). An initial attempt to provide a solution, regarding the interoperability of $3 \mathrm{D}$ geovisualization, was the following services: Web 3D Service (W3DS) and Web View Service (WVS). The OGC 3DPS combines the essential parts of the aforementioned proposed Web services into a common interface and thus, it could provide either 3D graphics data or rendered images (Hagedorn et al., 2017). In 2018, several experiments were presented by the OGC testbed 13 Engineering Report documents (Coors, 2018). The main goal of this report was to test and validate the interoperability of the OGC 3DPS, using 3DPS implementation instances to generate web-based visualizations with a workflow that used CityGML as data sources and 3D Tiles and I3S as data delivery formats. This report summarizes a proof-of-concept of the use of 3D Tiles and I3S as data delivery formats for the OGC 3DPS interface standard (Koukofikis et al., 2018). It should be noted that the commercial solutions for sharing 3D content using the I3S as a data delivery format is the ArcGIS Scene service, which is provided via the ArcGIS server of ESRI. This approach was implemented by Pispidikis et al. (2018), combining different 3D modelling methodological tools and techniques to develop a semantically enriched $3 \mathrm{D}$ campus model that can be used for navigation and maintenance purposes.

3.3.2. OGC Web Feature Service (WFS): Retrieving CityGML data via OGC WFS 2.0 presents a number of technical problems relating to the characteristics of the CityGML and the fact that CityGML schema is much more complex than those usually deployed in WFS. For that reason, the extension of the OGC WFS 2.0 has been further examined and implemented so that the complex structure of CityGML can be successfully retrieved (Curtis, 2008; Yao et al., 2018; Zhu, et al, 2016; Pispidikis and Dimopoulou, 2016).

3.3.3. REST-based Web Services: REST as a different approach to provide access to data, can be used to provide end users with a guided, pre-packaged way of accessing data or resources. On the other hand, WFS, as a query language, enables end users to submit any type of supported WFS request. As a result, due to the limitless nature of WFS, difficulties in query optimization can arise. As a result, REST can be utilized to steer the end user towards a predefined pattern of access such as tiles, collections and IDs. The Snowflake Software (2016) presented the GO publisher RESTful service as a simple web interface which works on top of the respective WFS providing specific url resources to the end users. REST-based architecture was adopted by the upcoming WFS version 3, now called OGC API-Features (Portele and Vretanos, 2018) and the CityGML RESTful Web service as well (Pispidikis and Dimopoulou, 2019). It should be noted that the REST-based architecture style was adopted by the new lightweight Web service called InterSensor Service (Chaturvedi and Kolbe, 2018), which allows users to connect and retrieve sensor data from multiple data sources. Additionally, the retrieval observation data can be encoded according to the standardized external interfaces such as OGC Sensor Observation Service and OGC SensorThings API (Moshrefzadeh et al. 2017). The latter is a very lightweight standard built on Web protocols and OGC SWE standards, and applies an easy-to-use RESTful interface and JSON-based data encodings. However, the InterSensor service does not currently support the retrieval of time series data that is stored in a 3DCityDB database based on Dynamizer ADE schema.Therefore, the CityGML RESTful Web service was upgraded to fill this limitation.

\section{IMPLEMENTATION OF A SEMANTIC ENRICHED SMART BUILDING USING DYNAMIZERS}

This section describes both the different scenarios that were evaluated between the variety of BIM and BEM software capabilities and the selected methodological approach in order to retrieve a semantical enriched 3D model based on CityGML Standard and the associated energy time-series data. Figure 1 graphically describes available approaches and tools to create 
enriched CityGML models with energy data from BIM using ADE Extensions.

To describe the ways of integrating and dynamically retrieving the energy dynamic city objects parameters, a 3D WebGIS viewer was developed that utilized the available static CityGML model and its corresponding dynamic time- series data stored in the extended 3DCityDB that support the Dynamizer ADE.

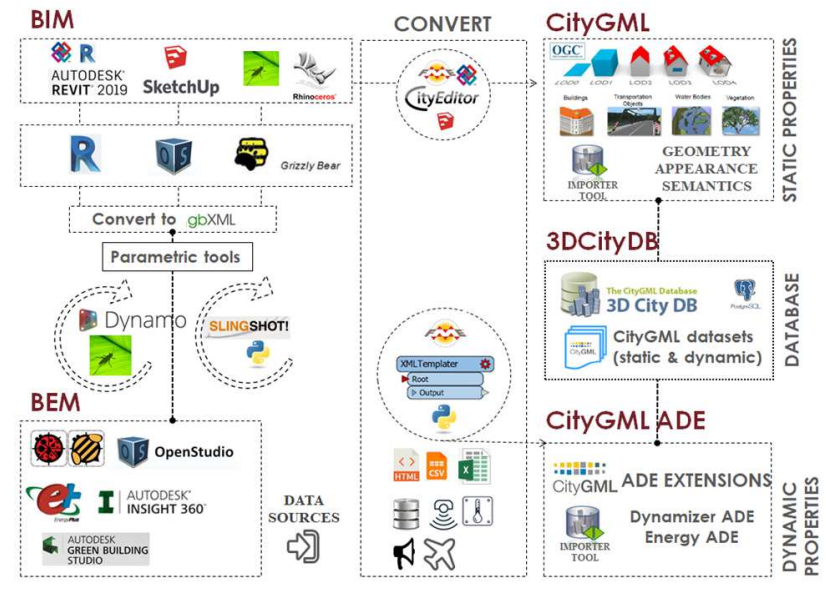

Figure 1. methodological approaches and tools' flowchart for CityGML energy modelling

4.1 3D Modelling development based on CityGML and integration of methodological approaches for simulated energy time-series

The energy data integration to the described city objects and their geometric characteristics was applied to the building Information Model (BIM) of Metsovio Interdisciplinary Research Center (MIRC) in Greece. MIRC consists of three buildings, the Dormitory Building (detailed case study), the Restaurant/Living Room and the main Building hosting labs and Seminar/ Conference halls. (Figure 2)

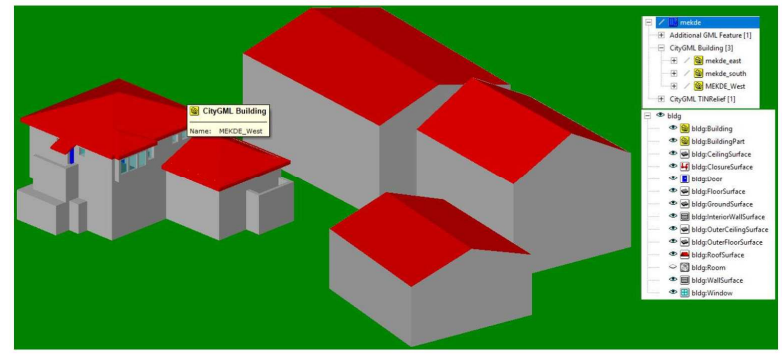

Figure 2. MIRC's three Buildings (in CityGML)

4.1.1 Building Energy Model and time-series retrieval: Evaluating the overall methodological approach of BEM capabilities, it seems that Building Energy Software (BES) (e.g., Green Building Studio, Ecotect, eQUEST, Insight 360, OpenStudio for SketchUp) runs the simulation analysis based on the exported gbXML of BIM tools (Revit, Rhino, SketchUp), as the interoperability between BIM and BES tools is mainly processed with the gbXML schema. Those BES structure capabilities are utilized to illustrate environmental simulations (such as daylight, sunlight and energy consumption analysis etc.). The parametric tools, Dynamo (Revit) and Grasshopper (Rhino), could also be used as BES, using validated simulation engines such as OpenStudio and
EnergyPlus (US Department of Energy). GrizzlyBear for Honeybee tool suggested being useful for loading a gbXML file to Grasshopper. The parametric tools Grasshopper and Dynamo could be connected to relational databases using SQL using their Open Source plug-in, Slingshot! The simulation outputs, .html, .xlsx, .epw or .sql files could be utilized for further analysis as descripted in Figure 1. Moreover, a variety of construction templates and building activity schedules for further parametric analysis could be set through the OpenStudio SketchUp Plug-in using the. osm output files of HB simulation.

Focussing on the case study, the graphical algorithm editor plugin of design tool Rhino Grasshopper3D (GH) and its free and open source environmental plugin, Honeybee (HB) were used for conducting the energy simulation for the purpose of retrieving the spatio- temporal time-series data for each room of the building (referred to thermal zones) that will later be connected to the 3D semantic Model CityGML. For the simulation analysis, the solid thermal zones of MIRC buildings were recreated based on the room of the extracted floor plans retrieved from Revit. This approach is accomplished in order to avoid geometrical incoherencies of the room boundary thermal conditions. The thermal zones are recognized as HBzones components into $\mathrm{GH}$. Using the HB plugin tool that utilizes OpenStudio and EnergyPlus softwares, the energy simulation of each HBzone of BEM was conducted. The simulation outcome was the Mean Radiant Temperature (MRT) describing for each room annual time-series data per hour.

4.1.2 Semantic enrichment of Building Information Model using CityGML: Revit BIM software was also used to retrieve the geometric information of the three-dimensional building. Next, this information was used to further process and correct the BIM within the SketchUp design program. The solid BIM geometries were corrected in order to be geometrically matched with b-rep geometries of CityGML (GML3) Standard. Also, the geometry of the 3D model was well organized into layers referring to the specific object class in CityGML, using the layer panel of SketchUp. Moreover, the CityEditor plugin of SketchUp was utilized to convert three buildings of MIRC to CityGML- based models. Specifically, the objects modelled using SketchUp were characterized by their thematic surface, the LoD value, and the geometry type (such as lodXMultiSurface and lodXSolid), while all surfaces of each surface were defined as BoundarySurfaces. Thereafter, the rooms were grouped based on their interior thematic surfaces (InteriorWallSurface, FloorSurface, CeilingSurface, Window and Door), thus creating GroupType for the class Room. Also, the GroupType of the building was similarly defined. Additionally, the model's openings (doors, windows) were categorized as GroupType. For their semantic, topological and geometric translation in compliance with CityGML specification, each opening was defined as 'Opening Boundary SurfaceType' of its wall. Consequently, the same BoundarySurfaceType ID was assigned to both the wall opening and the wall itself. The CityGML components (such as BoundarySurfaceType ID, polygonID, LinearRingID) were automatically settled by the CityEditor plugin for the rest of the surfaces. Then, for each GroupType (Room, Building) was given attributes according to the Code lists of CityGML 2.0 specification. The exported CityGML file was already geolocated by the CityEditor on initial stage through the Geolocator tool in SketchUp. As a result, the Guest House was LoD4, while the adjacent buildings (Restaurant, Workshop and Seminar Building) were LoD2. The alternative (suggested in Figure 1) to use the IFC file $r$ to be converted to CityGML through FME software, was not implemented as, based on the 
above-mentioned studies, the more sophisticated the model is, the more geometrical ambiguities could be resulted with regard to LoD4.

4.1.3 Dynamizer ADE implementation into 3DCityDB: The CityGML created was stored in the 3D City Database (3DCityDB; Yao et al., 2018) through the Java-based application, 3DCityDB Importer/Exporter tool. Specifically, the PostgreSQL/PostGIS Database was used in compliance with the 3DCityDB schema. Moreover, the extension of the CityGML model for supporting the available energy time series data was implemented via the Dynamizer ADE. It should be noted that 3DCityDB v 4.2 (3DCityDB, 2019) includes the ADE Plugin Manager for its Importer/Exporter, which was used to extend dynamically the implemented 3DCityDB instance to facilitate the storage and management of time-series data arbitrary CityGML ADEs (Yao et al., 2017), such as Dynamizer ADE. The created tables of Dynamizers were structured based on the suggested Relational Database Model of Dynamizer ADE (Chaturvedi et al., 2019). The input time-series data in 3DCityDB were (i) MRT of each room, (ii) the real measurements of oil consumption of the building and (iii) the weather data from the adjacent meteorological station. For that purpose, a python script was developed and the available timeseries data was automatically imported into the corresponding extended tables of the 3DCityDB and connected to the semantic features of the model. An alternative approach for the generation of the CityGML instance document including the Dynamizer ADE could be the implementation of the FME transformer 'XMLTemplater' (OGC FCP1, 2016) (Figure 1). Thereafter, the said CityGML file could be imported to 3DCityDB by utilizing the ADE Plugin Manager of the 3DCityDB importer/ exporter tool. However, this approach has not been implemented since there is no ready-to-use plugin for the Dynamizer ADE.

\subsection{Web-based 3D energy model visualization and time-} series data retrieval

The methodological steps to develop a 3D WebGIS viewer, so that the available energy models can be portrayed, and the respective time series data can be dynamically retrieved based on the corresponding GML identifier (gmlid) of these models, were further described and are schematically presented in Figure 3.

Initially, the available energy models were exported from the 3DCityDB and converted into KML format, using the 3DCityDB importer/exporter tool. Next, the KML models were imported into a file Geodatabase which was structured based on the 3DCIM (3D City Information Model) schema, which is the commercial solution of the semantically enriched database schema (Padsala \& Coors, 2015). The terrain model was converted to geotiff and published as an elevation service, while the buildings models were converted to SLPK format and published as ArcGIS scene services. It should be noted that both services contain the respective gmlid as an attribute value.

The interoperable and easy-to-use time series data retrieval is achieved by extending the CityGML RESTful Web service. Namely, the "ADE_dynamizers" main resource was embedded and thus, the available CityGML features that contain time series data can be retrieved in JSON format. Thereafter, by using the respective gmlid as a sub-resource, the available time series data of these features can be retrieved as well. The JSONbased schema for the data retrieval using the "ADE_dynamizers" resource is presented in Figure 4-(b) and the conceptual design of the "ADE_dynamizers" resource with the available properties is shown in Figure 4-(a).

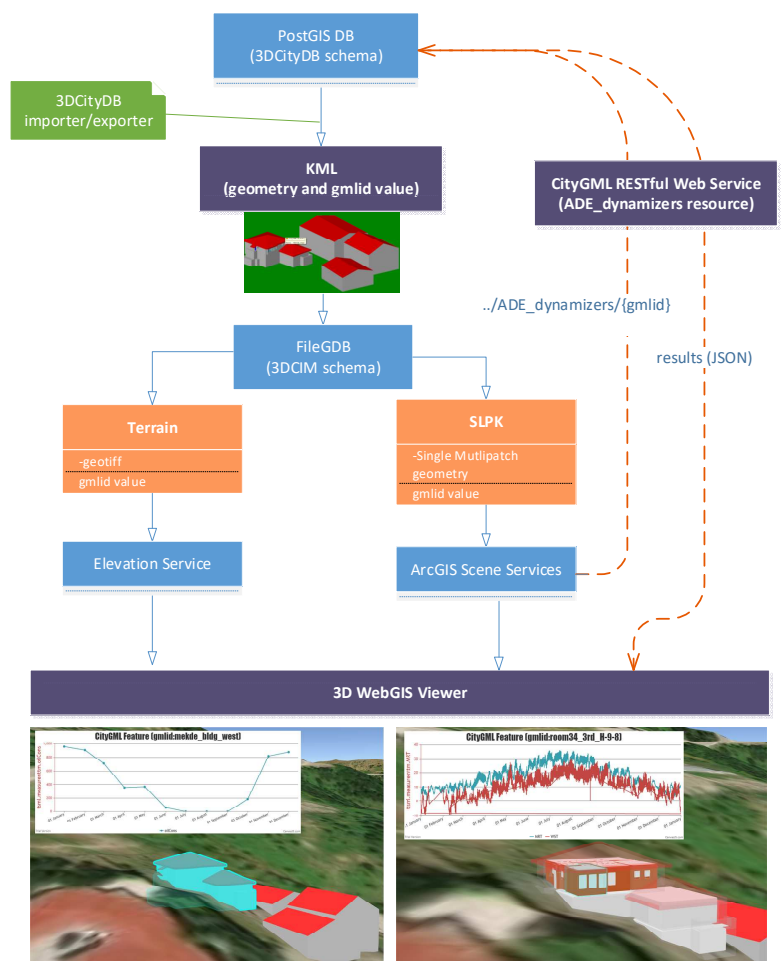

Figure 3. Methodological steps

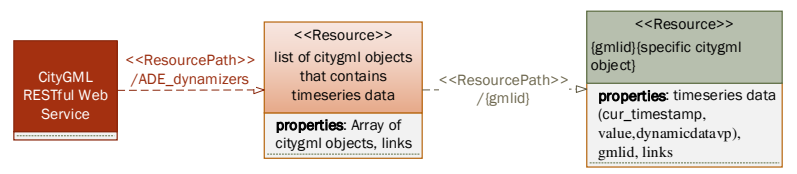

(a)

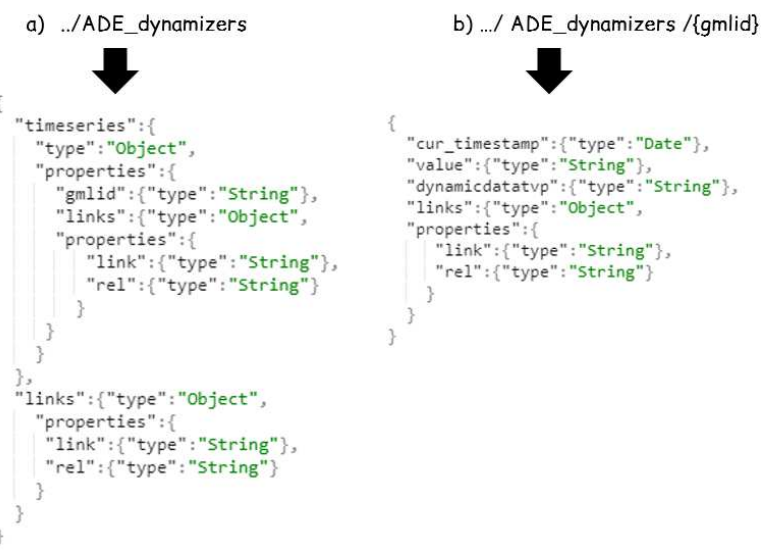

(b)

Figure 4. Conceptual model (a) and JSON-based schema (b) of the "dynamizers" main resource

As a result, the published services were integrated into a 3D WebGIS viewer and then, by selecting each of these services, the respective gmlid value was obtained. Thereafter, it could be used as a sub-resource endpoint for retrieving and plotting the corresponding time-series data.

\subsection{Results}

Due to the geometrical inconsistencies of translating BIM to $\mathrm{gbXML}$, the most reliable way to create a usable BEM from 
BIM was to redraw key aspects of the geometry by extruding up the model from the floor plans.

With regard to the BIM to CityGML conversation, since the described features have been well organized into layers in SketchUp, the CityEditor tool semi-automating the transformation procedure saving time and avoiding geometrical incoherencies at LoD4. However, with respect to the geometrical correction of BIM, the SketchUp tool editing capabilities proved not to be the optimal solution, as the surfaces that may overlap or be bisected by surfaces were not visible to the user. Finally, extending the CityGML Standard proved to be the optimal solution to this case study for the integration and visualization of the time-based energy simulation results with the static $3 \mathrm{D}$ building model, and thus, the conversion of the BIM model to CityGML is an important step for the current methodology approach.

With regards to the Web visualization of the $3 \mathrm{D}$ city models in different LoDs, the scene layer package format was implemented, which was shared as ArcGIS Scene service, while for time-series data retrieval, the CityGML RESTful Web service was upgraded and used. It should be noted that InterSensor service was considered the optimal solution for retrieving sensor data from distributed resources. However, it was not implemented because it does not currently support the time-series retrieval from the Dynamizer ADE schema of a 3DCityDB database.

\section{DISCUSSION AND FUTURE RESEARCH}

The Dynamizer ADE proved useful for integrating the input time-series data to the city objects. However, it was not fully researched in the current paper. Therefore, the remaining potential of Dynamizer ADE, such as the representation of realtime sensor observations either inline as atomic time-series or by linking to external sensor-based services, will be considered in future research work. Additionally, the upcoming version 3 of CityGML will integrate the dynamizer as basic thematic module with similar capabilities to the Dynamizers ADE. As a result, it can be implemented by the CityGML RESTful Web service similar to the "ADE_dynamizers" resource.

Furthermore, a python script was developed to achieve the storage of the time-series data into the 3DCityDB database. In future research work, this script will be replaced by a tool that will be developed according to the ADE Plugin Manager of the 3DCityDB importer/ exporter tool.Additionally, the InterSensor service supports the encoding of the observation data according to the standardized external interface from the OGC SWE. This facilitates the visualization of heterogeneous observations in a common framework. However, since this capability is not supported by the "ADE_dynamizers" main resource of CityGML RESTful Web service, it will be investigated into future research work.

\section{ACKNOWLEDGEMENTS}

The authors would like to thank Ordnance Survey GB (https://www.ordnancesurvey.co.uk) and 1Spatial (https://1spatial.com/) for sponsoring the publication of this paper.

\section{REFERENCES}

Agugiaro, G., Benner, J., Cipriano, P., Nouvel, R., 2018. The Energy Application Domain Extension for CityGML: enhancing interoperability for urban energy simulations. Open Geospatial Data, Software and Standards, 3(1), 2.

Athanasiou, K., Pispidikis, I., Dimopoulou, E., 2018. Semanticbased Technologies for Interoperable BIM and GIS 3D Modelling, Storage and Retrieval. FIG Commission 3 Annual Meeting and Workshop 2018, 3-6 December, Italy, Naples

Batty, M., Axhausen, W., K., Giannotti, F., Pozdnoukhov, A., Bazzani, A., Wachowicz, M., Ouzounis, G. \& Portugali, Y., 2012. Smart cities of the future. The European Physical Journal Special Topics, pp. 481-518.

Bazjanac, V., 2009. Implementation of semi-automated energy performance simulation: Building geometry, Cib W78.

Boyes, G., Ellul, C. and Irwin, D., 2017. Exploring BIM For Operational Integrated Asset Management- A Preliminary Study Utilising Real-World Infrastructure Data. In: ISPRS Annals of the Photogrammetry, Remote Sensing and Spatial Information Sciences, Volume IV-4/W5. 12th 3D Geoinfo Conference 2017, Melbourne, Australia.

Chaturvedi, K., Yao, Z., \& Kolbe, T. H., 2015. Web based Exploration of and Interaction with Large and Deeply Structured Semantic 3D City Models using HTML5 and WebGL. In Wissenschaftlich-Technische Jahrestagung der DGPF und Workshop on Laser Scanning Applications (Vol. 3).

Chaturvedi, K., \& Kolbe, T. H., 2016. Integrating Dynamic Data and Sensors with Semantic 3D City Models in the context of Smart Cities. ISPRS Annals of Photogrammetry, Remote Sensing and Spatial Information Sciences, IV-2/W1, 31-38. https://doi.org/10.5194/isprs-annals-IV-2-W1-31-2016

Chaturvedi, K., Willenborg, B., Sindram, M., \& Kolbe, T. H., 2017. Solar Potential Analysis and Integration of the timedependent simulation results for semantic 3D City Models using Dynamizers. ISPRS Annals of Photogrammetry, Remote Sensing and Spatial Information Sciences, IV-4/W5, 25-32. https://doi.org/10.5194/isprs-annals-IV-4-W5-25-2017

Chaturvedi, K., Yao, Z., \& Kolbe, T. H. 2019. Integrated Management and Visualization of static and dynamic properties of semantic 3D City Models. ISPRS - International Archives of the Photogrammetry, Remote Sensing and Spatial Information Sciences, XLII-4/W17, 7-14. https://doi.org/10.5194/isprsarchives-XLII-4-W17-7-2019

Chaturvedi, K., \& Kolbe, T. H., 2018. Intersensor service: Establishing interoperability over heterogeneous sensor observations and platforms for smart cities. In 2018 IEEE International Smart Cities Conference (ISC2) (pp. 1-8). IEEE.

Chaturvedi, K., \& Kolbe, T. H., 2019. A requirement analysis on extending semantic 3D City Models for Supporting timedependent properties. ISPRS Annals of Photogrammetry, Remote Sensing and Spatial Information Sciences, IV-4/W9, 19-26. https://doi.org/10.5194/isprs-annals-IV-4-W9-19-2019

Cozzi, P, Lilley, S., Getz, G., 2019. OGC 3D Tiles Specification. Version 1.0. (OGC Document Number 18-053r2)

Coors, V., 2018. OGC Testbed-13: 3D Tiles and I3S Interoperability and Performance ER (OGC Document Number 17-046) 
Curtis, E., 2008. Serving CityGML via web feature services in the OGC web services-phase 4 testbeds. Journal of Advances in 3D geoinformation systems, 331-340

Fernald, H., Hong, S., Bucking, S., \& O’Brien, W., 2018. BIM to BEM translation workflows and their challenges: A case study using a detailed BIM model. 10.

Floros, G. S., Ellul, C., \& Dimopoulou, E., 2018. Investigating Interoperability between IFC and CityGML LOD 4 - Retaining Semantic Information. ISPRS - International Archives of the Photogrammetry, Remote Sensing and Spatial Information Sciences, XLII-4/W10, 33-40. https://doi.org/10.5194/isprsarchives-XLII-4-W10-33-2018

Geiger, A., Benner, J. Hafele, H., Hagenmeyer V., 2018. Thermal Energy Simulation of Buildings Based on the CityGML Energy Application Domain Extension. Institute for Automation and Applied Informatics, Karlsruhe Institute for Technology, Karlsruhe,Germany

Gutbell, R., Pandikow, L., Coors, V., \& Kammeyer, Y., 2016. A framework for server side rendering using OGC's 3D portrayal service. In Proceedings of the 21st International Conference on Web3D Technology (pp. 137-146). ACM.

Hagedorn, B., Thum, S., Reitz, T., Coors, C., Gutbell R., 2017. OGC® 3D Portrayal Service. Version 1.0 (OGC Document Number 15-001r4)

IFC, 2016. Industry Foundation Classes Version 4 - Addendum 2. http://www.buildingsmart-tech.org/ifc/IFC4/Add2/html/ (10 April 2019).

Ivanova, I., Kiesel, K. and Mahdavi, A., 2015. BIMgenerated data models for EnergyPlus: A comparison of gbXML and IFC Formats, in IBPSA Building Simulation Conference. Hyderabad, pp. 407-414.

Khronos Group, 2019. glTF Specification Webpage. Retrieved from Khronos Group (2019): https://www.khronos.org/gltf.

Koukofikis, A., Coors, V., \& Gutbell, R., 2018. Interoperable visualization of 3D city models using OGC's standard 3D portrayal service. ISPRS Annals of Photogrammetry, Remote Sensing \& Spatial Information Sciences, 4(4).

Lilis, G. N., Rovas, D. V., \& Prieto, I., 2016. Second-level space boundary topology generation from CityGML inputs. In Proceedings of the 3rd Building Simulation and Optimisation Conference (Vol. 2016, pp. 297-304). IBPSA-England.

Moshrefzadeh, M., Chaturvedi, K., Hijazi, I., Donaubauer, A., \& Kolbe, T. H., 2017. Integrating and Managing the Information for Smart Sustainable Districts-The Smart District Data Infrastructure (SDDI). 19.

Mignard, C., \& Nicolle, C., 2014. Merging BIM and GIS using ontologies application to urban facility management in ACTIVe3D. Computers in Industry, 65(9), 1276- 1290.

OGC FCP1, 2016. Future City Pilot Phase 1, http://www.opengeospatial.org/projects/initiatives/fcp1. (Accessed 1 June, 2017)
Ohori, K. A., Biljecki, F., Kumar, K., Ledoux, H., \& Stoter, J., 2018. Modeling cities and landscapes in 3D with CityGML. In Building Information Modeling (pp. 199-215). Springer, Cham.

Padsala, R., Coors, V., 2015. Conceptualizing, Managing and Developing: A Web Based 3D City Information Model for Urban Energy Demand Simulation. In: UDMV, pp. 37-42.

Pispidikis, I. \& Dimopoulou, E., 2019. Conceptual model of CityGML RESTful Web Service, Int. Arch. Photogramm. Remote Sens. Spatial Inf. Sci., XLII-4/W15, 67-74, https://doi.org/10.5194/isprs-archives-XLII-4-W15-67-2019.

Pispidikis, I., Tsiliakou, E., Kitsakis, D., Athanasiou, K., Kalogianni, E., Labropoulos, T., and Dimopoulou, E., 2018. Combining methodological tools for the optimum 3D modelling of NTUA campus, ISPRS Ann. Photogramm. Remote Sens. Spatial Inf. Sci., IV-4/W6, 57-63, https://doi.org/10.5194/isprsannals-IV-4-W6-57-2018.

Pispidikis, I. and Dimopoulou, E., 2016. Development of a 3d WebGIS system for retrieving and visualizing CityGML data based on their geometric and semantic characteristics by using free and open source technology, ISPRS Ann. Photogramm. Remote Sens. Spatial Inf. Sci., IV-2/W1, 47-53, https://doi.org/10.5194/isprs-annals-IV-2-W1-47-2016.

Portele, C., 2019. OGC Testbed-14 Next Generation APIs: Complex Feature Handling Engineering Report. Retrieved from http://docs.opengeospatial.org/per/18-021.html (April 2020)

Prandi, F., Devigili, F., Soave, M., Di Staso, U., \& De Amicis, R., 2015. 3D web visualization of huge CityGML models. ISPRS International Archives of the Photogrammetry, Remote Sensing and Spatial Information Sciences, 1, pp. 601-60

Reed, C., Belayneh, T., 2017. OGC Indexed 3d Scene Layer (I3S) and Scene Layer Package Format Specification. Version 1.0. (OGC Document Number 17-014r5).

Schilling, A., Bolling, J., \& Nagel, C., 2016. Using glTF for streaming CityGML 3D city models. In Proceedings of the 21st International Conference on Web3D Technology (pp. 109-116). ACM.

Snowflake Software. (2016). GO Publisher WFS Documentation. Introducing REST Services. Retrieved from Snowflake Software, 2020.: https://wiki.snowflakesoftware.com/display/GPWFSDOC/Intro ducing REST Services.

Yao, Z., Nagel, C., Kunde, F., Hudra, G., Willkomm, P., Donaubauer, A., ... \& Kolbe, T. H., 2018. 3DCityDB-a 3D geodatabase solution for the management, analysis, and visualization of semantic 3D city models based on CityGML. Open Geospatial Data, Software and Standards, 3(1), 1-26.

Yin, C., Xiong, Z., Chen, H., Wang, J., Cooper, D., David, B., 2015. A Literature Survey on Smart Cities. Science China Information Sciences, 58(10), 1-18.

Zhu, W., Simons, A., Wursthorn, S., Nichersu, A., 2016. Integration of CityGML and Air Quality Spatio-Temporal Data Series via OGC SOS. In Proceedings of the Geospatial Sensor Webs Conference (GSW), Munster, Germany (pp. 29-31). 